\title{
Research of Grid-connected Inverter Based on SVPWM Control Strategy Fang Zhao ${ }^{1, a^{*}}$, Haiyun Zhu', b and Long Chen ${ }^{2, c}$ \\ ${ }^{1}$ Zhengzhou Technical College, Zhengzhou 450121, China \\ ${ }^{2}$ The Fourth Construction of China Machinery Industry CO, LTD. azhaojifang216@126.com, b33645975@qq.com, c491758574@qq.com
}

Keywords: Inverter; AC inductance; DC magnetic bias; SVPWM control

\begin{abstract}
In order to reduce the total harmonic distortion of grid-connected inverter, according to the working principle of three-phase inverter, establish the mathematical model in the three-phase static coordinate system, study the SVPWM modulation technology used in three-phase inverter. Provide the inductance parameter selection principle under this kind of control technology, analyses the different connection of the secondary side and DC magnetic bias influence on total harmonic distortion, proposed the improved method. Simulate a three-phase inverter used SVPWM modulation strategy under the Matlab/Simulink environment; build a three-phase inverter experimental prototype based on DSP control, and carry out the grid experiment. The experimental and simulation results show the feasibility of the research methods and control strategies.
\end{abstract}

\section{Introduction}

Distributed generation, such as wind power, photo electricity, and DC battery energy storage technology is developing with full speed; it can ease excess demand on the power grid and deal with the interruption or widespread blackouts etc. Grid-connected inverter is an important part in the distributed generation system; its circuit structure; grid-connected type and control strategy directly affect the quality of power supply [1].

Literature [2] adopts the SPWM control strategy and achieves good control effect, but the SPWM leads to low utilization rate of DC side voltage. The effect of inverter grid studied in the literature 3 is good, but it uses the interconnection of secondary side utilized Y connection which can create the third harmonic to make pollution to grid current. Based on the common three-phase inverter circuit, this paper establishes its mathematical model, uses the voltage space vector (SVPWM) modulation control strategy to improve the efficiency of the DC voltage, introduces AC current feedback loop in the control system and gives the parameter selection of the filter inductance on the inverter AC side combined with SVPWM control method. Grid transformer secondary side adopts the triangle connection method, eliminates the third harmonic and introduces in the amount of DC bias feedback in control system, so that the grid current harmonic content significantly reduced and Power grid voltage has good tracking results. The control strategy and parameter selection is validated by using Matlab / Simulink simulation and building a real prototype $[3,4]$.

\section{General Mathematical Model of Three-phase Inverter Control Strategy and Analysis}

General Mathematical Model of Three-phase Inverter. Grid-connected inverter main circuit topology structure as shown in Fig. 1. The main circuit is composed by DC power supply, three-phase Inverter Bridge, LC filter circuit, and girds transformers and AC contactor. $v_{d c}$ represents the DC Power emf, $i_{a} 、 i_{b}, i_{c}$ represents the ac current of inverter, $e_{a}, e_{b}, e_{c}$ represents Grid emf, L、C represents AC side filter inductance and capacitance , R represents the AC load. There are three groups bridge arm in the main circuit. They are consisted by six power switch tube and the switch state is symmetrical. 


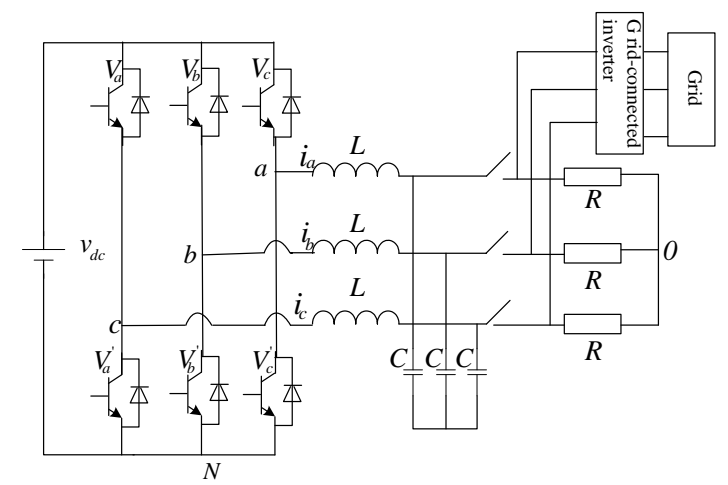

Figure 1. Three-phase gird-connected inerter topology

Switching function $S_{j}(j=a, b, c)$ is used to describe the state of six switch tube. When $S_{j}=$ $1(j=a, b, c)$, the above switch is on and the following switch is off. When $S_{j}=1(j=a, b, c)$, the following switch is on and the above switch is off. Thus, the mathematical model of the inverter in $a b c$ coordinate system are shown as follows:

$$
\begin{aligned}
& L \frac{\mathrm{d} i_{a}}{\mathrm{~d} t}+R i_{a}=e_{a}-\left(S_{a}-\frac{S_{a}+S_{b}+S_{c}}{3}\right) v_{d c} \\
& L \frac{\mathrm{d} i_{b}}{\mathrm{~d} t}+R i_{b}=e_{b}-\left(S_{b}-\frac{S_{a}+S_{b}+S_{c}}{3}\right) v_{d c} \\
& L \frac{\mathrm{d} i_{c}}{\mathrm{~d} t}+R i_{c}=e_{c}-\left(S_{c}-\frac{S_{a}+S_{b}+S_{c}}{3}\right) v_{d c}
\end{aligned}
$$

According to needs of control strategy, the mathematical model in $a b c$ coordinates is transformed into the two phase rotating coordinate system through coordinate transformation, as shown below:

$$
\begin{aligned}
& L \frac{d i_{d}}{d t}=e_{d}-R i_{d}-S_{\alpha} v_{d c}+\omega L i_{q} \\
& L \frac{d i_{q}}{d t}=e_{q}-R i_{q}-S_{q} v_{d c}-\omega L i_{d}
\end{aligned}
$$

Control Strategy Analysis. According to the Eq. 4 and Eq. 5, the control block diagram in this paper adopted as shown in Fig. 4.The DC power source electromotive force $v_{d c}$ is turned into the given value $i_{d}^{*}$ of current active component by PI regulation. the power grid voltage $e_{a} 、 e_{b} 、 e_{c}$ and three phase current $i_{a} 、 i_{b} 、 i_{c}$ are collected ,transformed into active component $e_{d} i_{d}$ and reactive component $e_{q} 、 i_{q}$ through the transformation between three-phase stationary two phase rotating coordinate, and respectively compared with $i_{d}^{*} 、 i_{q}^{*}$. The result is put into the PI regulator, decoupling link and then get the voltage dc component $v_{d}^{*}$ and $v_{q}^{*} \cdot v_{d}^{*}$ and $v_{q}^{*}$ change into $v_{\alpha}$ and $v_{\beta}$ under the two-phase static coordinate system through the coordinate transformation. Minus the DC bias $v_{i p}$ on the $v_{\alpha}$ and then put the result and $v_{\beta}$ into the judgment of the sector SVPWM to produce PWM wave to control power switch tube switch state and switching time. 


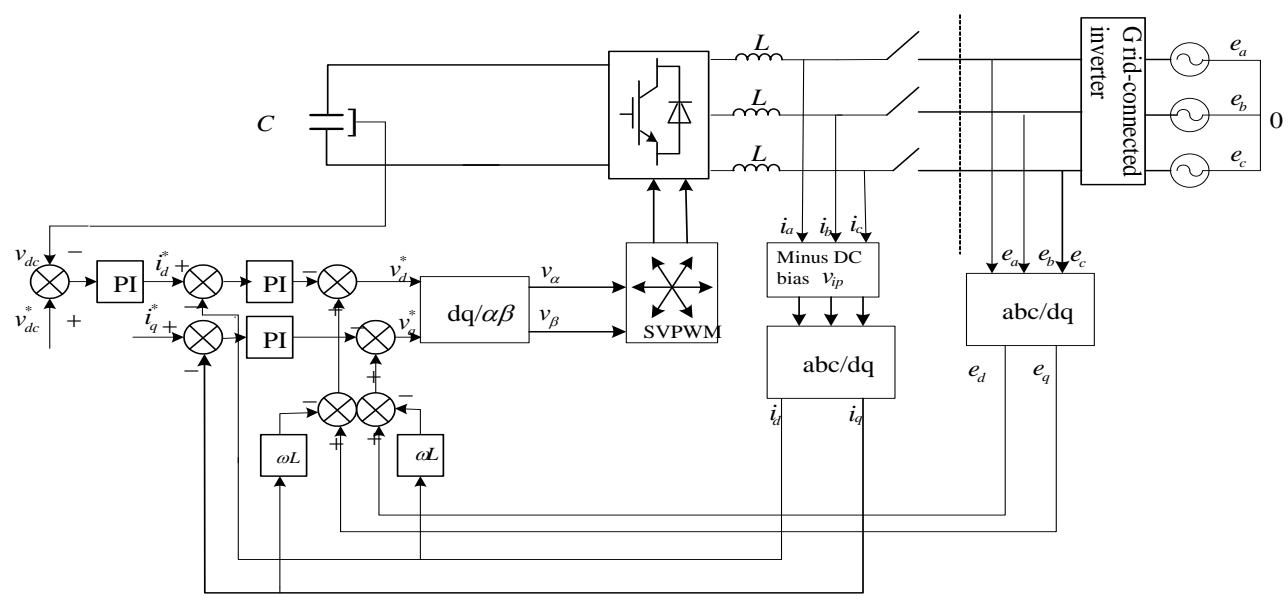

Figure 2. Grid-connected inverter control strategy diagram

The cause of the DC magnetic bias mainly includes: magnetic circuit saturation, asymmetric AC three-phase circuit, filter inductor saturation, error of the Hall sampling circuit, asymmetry of the power switch bridge arm, PWM dead zone time and temperature drift phenomenon of hardware circuit[5,6], etc.

The DC magnetic bias caused by transformer magnetic circuit saturation can use the secondary side of the triangle connection eliminates. The cause of asymmetric AC three-phase circuit and filter inductor saturation can minus the stages were measured respectively DC bias before the data processing.

The principle of SVPWM control strategy is use six power switch tube states and combination of different states in Figure 1 to realize the space voltage vector control, and then ajust the frequency of switch tube to ensure the voltage space vector can nearly working in circular orbit. The results are shown by low harmonic distortion and high utilization rate.

The six power switch tube can be assembled into eight kinds of state to form the basic voltage space vector. Based on the characteristics of those phase Angle, respectively named $O_{000}, U_{0}, U_{60}, U_{120}, U_{180}, U_{240}, U_{300}, O_{111} . O_{000}$ and $O_{111}$ are called zero vectors. Using six basic non-zero voltage space vector linear times combination can get more switch states and obtain the actual work required for data processing in the round rotating magnetic field. In each $T_{P W M}$ period, changing the working time of the adjacent basic vector and ensuring the amplitude of new voltage space vector are equal. As long as $T_{P W M}$ is short enough, the voltage space vector trajectory is approximate to circular [7].

\section{AC Filter Circuit Inductance Parameter Selection}

Inductance value of the filter circuit directly affects the harmonic content of the grid side current, so two problems should be taken into account on the inductance selection. Firstly, satisfying the AC vector relation on the steady state to ensure that the system is running in high power factor conditions. Secondly, to achieve the transient state current tracking index, which requires the value of inductance can be adapted to current and restrained the influence of harmonic. According to calculation of inductance parameters selection in Ref. [5], there are two indicators to determine the scope of filter inductance. When the indicators meet steady state circuit, the upper limit of range inverter side inductance value is

$$
L \leq \frac{E_{m} \sin \varphi+\sqrt{E_{m}^{2} \sin ^{2} \varphi+V_{m}{ }^{2}-E_{m}^{2}}}{\omega I_{m}}
$$

When meet the transient current tracking index, it is concluded that the lower limit of the range inductance value is

$$
L \geq \frac{\left(2 v_{d c}-3 E_{m}\right) E_{m} T_{s}}{2 v_{d c} \Delta i_{\max }}
$$

In the Eq. 6 and Eq. 7, $E_{m}$ is phase voltage peak value of power grid; $I_{m}$ is AC current peak 
value of rectifier; $V_{m}$ is $\mathrm{AC}$ voltage peak value of rectifier; $T_{s}$ is $\mathrm{PWM}$ cycle; $v_{d c}$ is DC electromotive force, $\Delta i_{\max }$ are maximum fluctuations of harmonic current. According to Eq. 6 and Eq. 7, ultimately determining the AC filter inductance value is $6 \mathrm{mH}$.

\section{Simulation and Experiment}

In order to verify the control performance of grid-connected inverter based on SVPWM, simulation models are built in MATLAB/Simulink according to the principle of Fig. 1 and Fig. 2 circuit control structure. The Fig. 3 shows that simulation platform consists of three phase AC power, LC AC filter circuit, three-phase power switch tube module and DC power supply. The simulation parameters settings as follows: the three-phase AC input phase voltage RMS is $220 \mathrm{~V}$, the frequency is $50 \mathrm{~Hz}$, the filtering inductance value is $6 \mathrm{mH}$, the capacitance value is $47 \mathrm{uF}$, the value of Rs is $1 \Omega$, and the simulation time is 0.5 seconds. Fig. 4 shows that the grid side current track grid voltage. The larger signal is grid side voltage amplitude, and the smaller one is grid side current $[8,9,10]$.

Fig. 5 is the grid side current signal harmonic analysis. Through the two figures we can see, the system achieved good effect about the current tracking grid side voltage the harmonic distortion rate of grid current is $1.02 \%$.

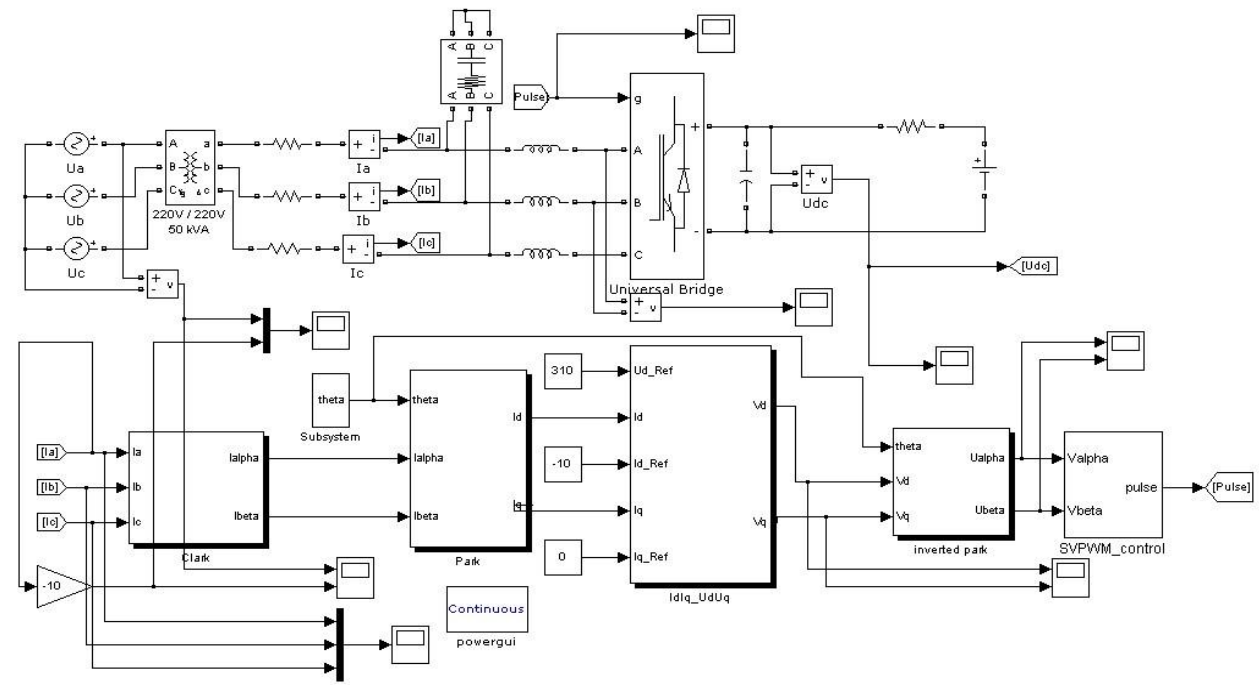

Figure 3. Simulation model circuit

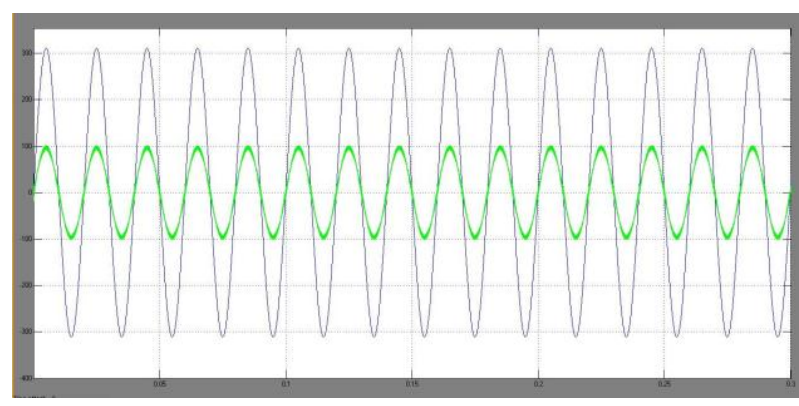

Figure. 4. Grid side current tracking voltage

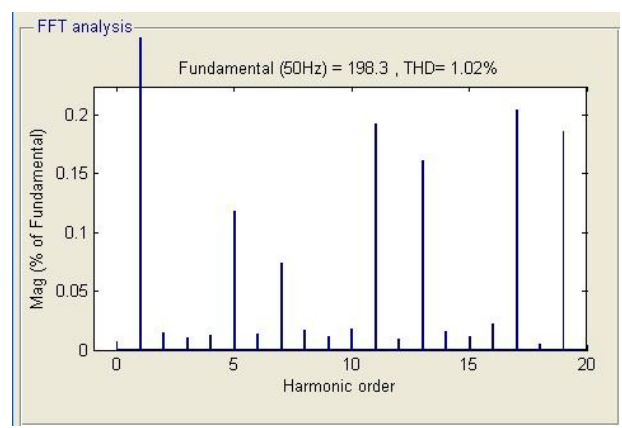

Figure 5. Analysis of the grid side current harmonics

Fig. 6 is the waveform of experimental prototype current tracking grid voltage. The slightly larger amplitude signal is the power grid voltage, and the smaller one is the grid-side current signal. In the experimental prototype system, interconnection of transformer secondary side adopts triangle connection method. The transformer variable ratio is $380 / 36$, the capacity is $300 \mathrm{VA}$, and the value of $\mathrm{AC}$ filter inductance is $6 \mathrm{mH}$. 


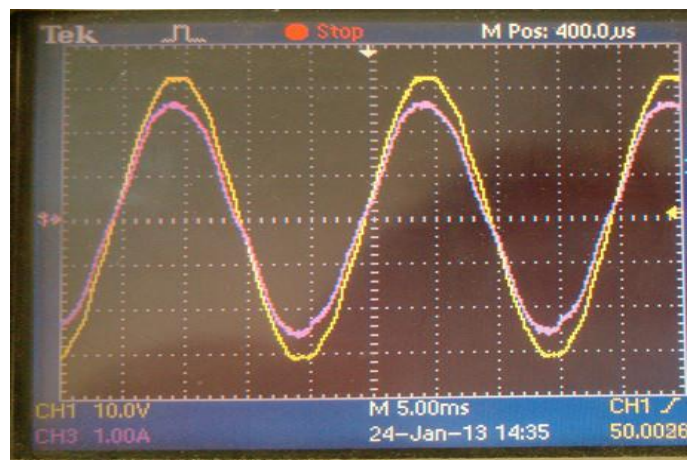

Figure 6. Experimental prototype grid side current tracking power grid waveform

Fig. 6 shows that the AC side current synchronizes with power grid after the inverter is connected to grid. The grid-connected current harmonic distortion rate is $4.77 \%$ which conforms to the national standard. In addition, the basis about magnetic circuit connection of the transformer secondary side as following: When the magnetic circuit of transformer core rises to the saturation condition, there are not only fundamental harmonic but also the third harmonic to be contained. When the secondary winding using the star connection, the third harmonic component can't be circulated, it can content increases the third harmonic in grid-side current. When the secondary winding using the triangle connection, the three-phase third harmonic electromotive force will produce third harmonic circulation in triangle closed loop, the third harmonic of grid-connected current can be well controlled.

\section{Conclusions}

Grid-connected inverter based on SVPWM control strategy have been studied from the selection of AC filter inductance, magnetic circuit of the transformer secondary side winding connection mode and DC bias in this paper. Some conclusions are as follows:

Firstly, when the indicators meet steady state and transient circuit index, the greater the inductance value in AC side, the better the filtering effect. Secondly, the transformer secondary winding triangle connection mode can greatly reduce the effects of third harmonic current of the whole system and harmonic distortion rate. Thirdly, the introduction of DC bias purifies the DC component of grid current. The simulation proves the feasibility of this theory. And the experimental results of prototype is further evidencing that the validity of theoretical analysis.

\section{Acknowledgements}

2016 annual science and Technology Department of Henan province science and technology development project. Number: 162102210334

\section{References}

[1] B.H. Zhang, J. Zeng, C.X. Mao, Y.J. Jin and Y.L. Wang: Power System Technology, Vol.30 (2006) No.15, p.54-58. (In Chinese)

[2] Z. Chen: Electrical Engineering, (2010) No.12, p.24-27. (In Chinese)

[3] G. Liu, Y. Liang, S.Q. Hu and W.Z. Yao: Power Electronics, Vol. 44 (2010) No.10, p.12-14.

[4] D.H. Li and X.C: Converter Technology \& Electric Traction, (2010) No.3, p.19-23. (In Chinese)

[5] F.Z. WU, J.R. Wan and H. Shen: Power Electronics, Vol. 43(2009) No.8, p.7-9. (In Chinese)

[6] J.Q. Wang, Q.J. Wang, G.L. Li, Q. Chen, G.L. Xu and L. Wei: Electric Drive, Vol.43 (2013) No.1, p.39-43. (In Chinese) 
[7] T.R. Chun, Y.H. Dong and Gyu H.cho: IEEE Trans. Ind. Appl., Vol.26 (1990) No.4, p.777-785.

[8] Santiago A. Verne and María I. Valla: Electric Power Systems Research, Vol.80 (2010), p. $1543-1551$.

[9] F.Z. WU and F. Zhao: Journal of Donghua University, Vol.89 (2009) N0.3, p.311-312. (In Chinese)

[10]F.Z. WU, Z.W Feng and L. Han: Electrical Engineering, Vol.0 (2015), No.11, p. 24-25. (In Chinese) 